\title{
Tratamiento de rescate de la infección por Helicobacter Pylori
}

María del Carmen Arias Núñez.

Servicio de Medicina Interna. Complejo Hospitalario Xeral - Calde (Lugo).

PALABRAS CLAVE: Helicobacter pylori, fracaso terapéutico y

rescate.

KEY WORDS: Helicobacter pylori treatment failure AND rescue

\section{Introducción}

La infección por Helicobacter pylori (H.pylori) es la principal causa de gastritis, enfermedad ulcerosa gastroduodenal y cáncer gástrico ${ }^{1}$. También se ha asociado con algunas enfermedades sistémicas como la trombocitopenia autoinmune, la anemia ferropénica y la urticaria crónica aunque su patogenia no es bien conocida².

Durante los últimos años, las recomendaciones respecto al tratamiento de $\mathrm{H}$. pylori no han experimentado grandes modificaciones, empleándose regímenes terapéuticos que proporcionen tasas de erradicación superiores al $80 \%{ }^{3}$. Los mayores avances se han centrado en la utilización de nuevos fármacos que han mostrado excelentes resultados en estudios preliminares y que permiten una aproximación más flexible al tratamiento de los pacientes que han presentado dos o más fracasos terapéuticos.

\section{Tratamientos erradicadores de primera elección en españa}

La combinación más ampliamente utilizada en nuestro país consta de un inhibidor de la bomba de protones (IBP, dosis habitual /12h), Amoxicilina $1 \mathrm{~g} / 12 \mathrm{~h}$ y Claritromicina $500 \mathrm{mg}$ $112 h .{ }^{3}$. La tasa de erradicación con esta pauta es del 85\% en pacientes con cepas susceptibles a la claritromicina y del 20\% en aquellos con cepas resistentes. En España la tasa de resistencia primaria a claritromicina se ha mantenido estable durante los últimos años, con cifras inferiores al $10 \%$, por lo que la eficacia de la pauta descrita debería mantenerse en torno al $80 \% 4$.

La combinación de ranitidina-citrato de bismuto (RCB) junto con dos antibióticos puede incluirse dentro de los tratamientos erradicadores de primera elección. RCB 400mg/12h + Amoxicilina $1 \mathrm{~g} / 12 \mathrm{~h}$ + claritromicina $500 \mathrm{mg} / 12 \mathrm{~h}^{3}$.

La tasa media de erradicación de H. pylori al asociar RCB con claritromicina y amoxicilina es del $82 \%$, mientras que la tasa correspondiente a la combinación de este fármaco con claritromicina y nitroimidazol es del $86 \%$.
Existen varios estudios aleatorizados que comparan IBP con RCB junto con claritromicina y amoxicilina, y se concluye que ambas alternativas son equivalentes. Sin embargo, cuando Ios antibióticos empleados son claritromicina y nitroimidazol, desmuestran con la RCB es superior a los IBP5.

En caso de alergia a la penicilina, la amoxicilina deberá sustituirse por metronidazol (500mg/12h). En este caso, probablemente se deba emplear RCB en lugar de un IBP3.

\section{Papel de los ibp en las pautas de erradicación}

Todos los IBP (omeprazol, lansoprazol, pantoprazol, rabeprazol y esomeprazol) son equivalentes cuando se utilizan con dos antibióticos para erradicar la infección por H. pylorí.

El tratamiento previo con un IBP no disminuye la eficacia posterior de las terapias triples con este antisecretor ${ }^{7}$.

Para obtener una elevada tasa de cicatrización ulcerosa duodenal es suficiente el empleo de un IBP durante una semana. No obstante, parece prudente que una úlcera duodenal complicada (ej. hemorragia digestiva) se administren antisecretores hasta confirmar la erradicación de H. pylori .

La escasa evidencia disponible sugiere que, tras haber finalizado el tratamiento erradicador, se debe prolongar el tratamiento antisecretor (entre cuatro y ocho semanas más) en las úlceras gástricas grandes (mayores de $1 \mathrm{~cm}$.); en las de pequeño tamaño es suficiente el tratamiento erradicador ${ }^{9}$.

\section{Duración del tratamiento erradicador}

En Europa hay una tendencia a recomendar tratamientos de una semana de duración, mientras en que EEUU la duración suele ser algo mayor, entre diez y catorce días.

Existe un estudio multicéntrico nacional en el que se ha comparado, con un diseño aleatorizado, siete frente a diez días de tratamiento erradicador con un IBP (rabeprazol), claritromicina y amoxicilina. En los pacientes con úlcera, las diferencias obtenidas con ambas pautas fueron mínimas, mientras que en los pacientes con dispepsia funcional se demostró una evidente superioridad de la pauta más lar$\mathrm{ga}^{10}$.

El siguiente paso consiste en evaluar si el incremento en la eficacia terapéutica que se consigue con la prolongación del 
tratamiento compensa el incremento de costes que supone. En nuestro medio, las pautas largas (diez días) han demostrado ser más coste-efectivas en pacientes con dispepsia funcional ${ }^{11}$.

\section{Tratamiento de rescate tras un primer intento erradicador}

El fracaso del tratamiento erradicador depende de varios factores: la resistencia bacteriana frente a alguno de los antibióticos empleados, el cumplimiento terapéutico (en duración y en dosis), las propiedades farmacológicas de los antibióticos, las características de las lesiones digestivas y la diferente patogenicidad de las cepas de H. pylori ${ }^{12}$.

Cuando ha fracasado el tratamiento de primera elección, se recomienda como terapia de rescate la siguiente pauta durante siete días: IBP (dosis habitual)/12h + Subcitrato de Bismuto (SB) 120mg/6h + Tetraciclina 500mg/6h + Metronidazol $500 \mathrm{mg} / 8 \mathrm{~h}^{6}$.

Esta pauta alcanza una eficacia erradicadora media del $78 \%{ }^{13}$.

La cuádruple terapia comporta una mayor incidencia de efectos secundarios, mayores dificultades para el cumplimiento, aumenta las posibilidades de desarrollar resistencias al emplear dos antibióticos y no siempre existe facilidad para disponer de subcitrato de bismuto ${ }^{14}$.

La sustitución del IBP y del compuesto de bismuto de la cuádruple terapia por RCB se asocia con resultados prometedores ${ }^{15}$.

\section{Fracaso de dos tratamientos erradicadores}

Una primera posibilidad ante el fracaso de dos tratamientos erradicadores es realizar cultivo y antibiograma para, en función de la susceptibilidad bacteriana, seleccionar la combinación antibiótica más adecuada, aunque su utilidad no ha sido suficientemente confirmada en la práctica clínica.

Por otra parte, existen una serie de argumentos para no realizar cultivo antes de indicar un tercer tratamiento erradicador ${ }^{16}$ :

- Realizar el cultivo implica someter al paciente a una endoscopia digestiva alta, lo que aumenta los costes.

- El cultivo no está disponible en todos los hospitales.

- La sensibilidad del cultivo bacteriano no es del 100\% y, por tanto, la susceptibilidad antibiótica no podrá conocerse en todos los casos.

- Sólo es posible valorar la sensibilidad sobre unos pocos antibióticos.

- Aún conociendo la sensibilidad bacteriana, no se alcanza una eficacia erradicadora del 100\%.

La actitud en estos casos parece clara: No reutilizar ninguno de los antibióticos frente a los que probablemente $\mathrm{H}$. pylori haya desarrollado resistencia ${ }^{6}$.
Hoy en día existen varias ALTERNATIVAS TERAPÉUTICAS en estos casos:

\section{LEVOFLOXACINO}

El levofloxacino es una fluoroquinolona con amplio espectro de actividad frente a bacterias grampositivas y gramnegativas. Posee in vitro una elevada actividad frente a $\mathrm{H}$. pylori y las resistencias primarias frente a este antibiótico son muy reducidas, en torno al $2 \%{ }^{17}$.

La combinación de un IBP, amoxicilina y levofloxacino (250mg/12h) como primer tratamiento ha alcanzado unas tasas de erradicación de aproximadamente el 90\%.

Sin embargo, se ha demostrado que la resistencia a quinolonas se adquieren fácilmente, y en países con elevado consumo de estos fármacos, las tasas de resistencias se han incrementado y son ya relativamente altas, de ahí su limitación como terapia de primera línea ${ }^{14}$,

Se ha evaluado también esta misma pauta durante 7-10 días en pacientes en los que previamente ha fracasado una terapia clásica, también con resultados esperanzadores, al describir tasas de erradicación que han oscilado entre el 63 y el $94 \%{ }^{18}$.

Un estudio reciente ha demostrado que la pauta de levofloxacino, amoxicilina y un IBP es más eficaz y mejor tolerada que la terapia cuádruple como alternativa de rescate tras el fracaso del tratamiento estándar ${ }^{19}$.

Cuando fracasan dos intentos erradicadores, las combinaciones basadas en levofloxacino podrían representar una alternativa. Así, en un estudio que evalúa la eficacia de una combinación de levofloxacino, amoxicilina y un IBP durante diez días en pacientes en los que habían fracasado al menos dos tratamientos previos, se alcanza una tasa de erradicación del 83\%. En España, la erradicación se cifra entre el 62 y el $75 \%$ en pacientes refractarios ${ }^{20,21}$.

El levofloxacino es un fármaco bien tolerado, y la mayoría de efectos adversos relacionados con su empleo son leves, transitorios y generalmente afectan al tracto gastrointestinal (nauseas, gusto metálico, dolor abdominal....). La incidencia de efectos secundarios en pautas con levofloxacino fue del $18 \%$ (3\% severos) $)^{22}$.

\section{RIFABUTINA}

La rifabutina es un antibiótico de reserva que se utiliza habitualmente para infecciones por micobacterias atípicas en pacientes inmunodeprimidos.

H. pylori ha demostrado ser muy susceptible in vitro a este antibiótico y no se ha aislado cepas resistentes a pesar de terapias erradicadoras previas ${ }^{17}$.

La experiencia con rifabutina en España va incrementándose progresivamente; así, en un estudio de 48 pacientes en los que tras el fracaso de dos líneas terapéuticas clásicas, se empleó un tercer tratamiento con IBP, amoxicilina y rifabutina (150mg/12h). 
La tasa de erradicación era superior al 65\%. Se describió la aparición de mielotoxicidad (neutropenia y/0 trombopenia) en el $10 \%$ de los pacientes, que se resolvieron espontáneamente tras finalizar el tratamiento ${ }^{23}$.

Entre los inconvenientes de esta terapia destacar su elevado coste, la posibilidad de mielotoxicidad y el riesgo de desarrollar resistencias.

Actualmente la triple terapia con levofloxacino durante diez días es más efectiva que el mismo tratamiento con rifabutina ${ }^{24}$.

\section{FURAZOLIDONA}

La furazolidona es un antibiótico activo frente a un amplio espectro de bacterias grampositivas y gramnegativas, así como frente a diversos protozoos.

Ha demostrado tener, en monoterapia, una elevada actividad antimicrobiana frente a $\mathrm{H}$. pylori y la mayoría de los tratamientos de primera línea que han incluído furazolidona han obtenido cifras de erradicación superiores al 80\%. El riesgo de desarrollar resistencias es muy bajo y no tiene resistencias cruzadas con el metronidazo ${ }^{17}$.

Inicialmente se demostró que una combinación cuádruple con furazolidona (200mg/12h), bismuto, tetraciclina y un IBP era considerablemente efectiva como tratamiento de segunda línea tras el fracaso de un primer intento erradicador ${ }^{17}$.

Estudios más recientes han evaluado esta cuádruple terapia como tratamiento de tercera línea, logrando la erradicación en el $90 \%$ de los casos $(n=18)^{25}$.

\section{Conclusiones}

Tras más de 20 años de experiencia en el tratamiento de la infección por H. pylori, no se ha encontrado ninguna pauta que asegure una tasa de curación del 100\%.

El tratamiento debe plantearse por tanto como una "estrategia terapéutica" que combine una pauta de primera línea con un tratamiento de rescate efectivo que no incluya ninguno de los antibióticos frente a los que probablemente H. pylori haya desarrollado resistencias. Así, si se emplean como tratamiento de primera línea pautas con claritromicina, se pueden emplear pautas de segunda línea con metronidazol y, en caso de necesitarse una tercera línea, pautas con levofloxacino. Se tiende a considerar que los tratamiento con levofloxacino constituyen una opción de segunda línea como alternativa a la cuádruple terapia dada su seguridad y la simplificación que suponen en el tratamiento; en estos casos la cuádruple terapia se reservaría como tercera línea. Los tratamientos con rifabutina y, en menor medida con furazolidona, constituyen alternativas de cuarta línea tras múltiples fracasos erradicadores.

En la literatura, el número de pacientes tratados con dos 0 más pautas de erradicación consecutivas es todavía escaso. Un estudio reciente realizado en nuestro país que incluye 500 pacientes seguidos en un único centro durante 10 años, muestra tasas de erradicación con tratamientos de rescate empíricos de segunda, tercera y cuarta líneas del 70, 74 y $76 \%$ respectivamente.

La realización de cultivo y antibiograma -incluso fras el fracaso de múltiples tratamientos erradicadores- no parece necesario en la práctica clínica.

\section{Bibliografía}

Suerbaum S, Michetti P. "Helicobacter pylori infection". N Engl J Med 2002; 347: 11751186.

Gasbarrini A, Franceschi F, Armuzzi A. "Extradigestive manifestations of Helicobacter pylori gastric infection". Gut 1999; 45: 9-12.

Gisbert JP, Calvet X, Gomollón F. "Tratamiento erradicador de Helicobacter pylori. Recomendaciones de la Conferencia Española de Consenso". Med Clin (Barc). 2000; 114:185-95.

Gisbert JP, Pajares JM. "Resistencia de Helicobacter pylori al metronidazol y a la claritromicina en España. Una revisión sistemática". Med Clin (Barc). 2001; 116: 111-6.

Gisbert JP, Calvet X, González L. "Systematic review and meta-analysis: proton pump inhibitors vs. ranitidine bismuth citrate plus two antibiotics in Helicobacte pylori erradication". Helicobacter, 2005; 10: 157-71.

Gisbert JP, Calvet X, Gomollón F. "Tratamiento erradicador de Helicobacter pylori. Recomendaciones de la II Conferencia Española de Consenso". Med Clin (Barc). 2005; 125(8): 301-16.

Annibale B, Dámbra G, Luzzi I. "Does pretreatment with omeprazole decrease the chance of eradication of Helicobacter pylori in peptic ulcer patients?" Am J Gastroenterol. 1997: 92:790-94.

Gisbert JP, Pajares JM. "Systematic review and meta-analysis: is 1-week proton pump inhibitor-based triple therapy sufficient to heal peptic ulcer?" Aliment Pharmacol Ther. 2005; 21:795-804.

Higuchi K, Fujiwara Y, Tominaga K. "Is eradication sufficient to heal gastric ulcers in patients infected with Helicobacter pylori? A randomized, controlled, prospective study". Aliment Pharmacol Ther. 2003; 17:111-7

Calvet X, Ducons J, Bujanda L. "Seven vs. ten-day of rabeprazol triple therapy for Helicobacter pylori eradication: a multicenter randomized trial". Am J Gastroenterol. 2005; 100(8):1702-3.

Gene E, Calvet X, Azagra R. "Seven days or ten? Cost-effectiveness study on the duration of $\mathrm{H}$ pylori treatment in primary care". Aten Primaria 2006; 38(10): 555-62.

Pajares García JM, Pajares Villarroya R, Gisbert JP. "Helicobacter pylori: resistencia a los antibióticos". Rev Esp Enferm Dig (Madrid) 2007;99(2):63-70

Calvet X, García N, Gene E. "Modified seven-day, quadruple therapy as a first time Helycobacter pylori treatment". Aliment Pharmacol Ther 2001; 15:1061-65.

Gisbert JP, Bermejo F, Castro-Fernández M. "Second-line rescue therapy with levofloxacin after H.pylori treatment failure: a Spanish multicenter study of 300 patients". Am J Gastroenterol 2008; 103: 71-76.

Gisbert JP, Fuentes J, Carpio D. "7-day resum therapy with bismuth citrate after Helicobacter pylori treatment failure". Aliment Pharmacol Ther. 2005; 21:1249-53.

Gisbert JP, Pajares JM. "Helicobacter pylori "rescue" therapy after failure of two eradication treatments. A review" Helicobacter. 2005; 10(5):363-72.

Megraud F, Lamouliatte H. "Review article: the treatment of refractory Helicobacter pylori infection". Aliment Pharmacol Ther. 2003; 17:1333-43.

Gisbert JP, Pajares JM. "Helicobacter pylori therapy: first line options and rescue regimen" Dig Dis. 2001; 19: 134-43.

Nista EC, Candelli M, Cremonini F. "Levofloxacin-based triple therapy vs quadruple therapy in second-line Helicobacter pylori treatment: a randomized trial" Aliment Pharmacol Ther. 2003; 18:627-33.

Gisbert JP, Bermejo F, Ducons J. "Tratamiento de rescate con levofloxacino tras múltiples fracasos erradicadores de H. pylori”. Gastroenterol Hepatol. 2005; 28:153.

Gisbert JP, Gisbert JL, Marcos S. "Empirical rescue therapy after H. pylori treatment failure: a 10 year single-center study of 500 patients". Aliment Pharmacol Ther 2008; 27: 346-354.

Gisbert JP, Morena F. "Systematic review and meta-analysis: Levofloxacin-based rescue regimen after Helicobacter pylori treatmente failure". Aliment Pharmacol Ther 2006; 23:65-44.

Gisbert JP, Bujanda L, Calvet X. "Tratamiento de rescate con rifabutina tras múltiples fracasos erradicadores de H. pylori". Gastroenterol Hepatol. 2005; 28:154.

Gisbert JP, Gisbert JL, Marcos S. "Third-line rescue therapy with levofloxacin is more effective than rifabutin rescue regimen after two Helicobacter pylori treatment failures". Aliment Pharmacol Ther 2006; 24: 1469-1474.

Treiber G, Ammon S, Malfertheiner P. "Impact of furazolidone-based quadruple therapy for eradication of Helicobacter pylori after previous treatment failures". Helicobacter. 2002; 7:225-31. 